\title{
USO DE INDICADORES DE EFICIÊNCIA ENERGÉTICA EM PLANTAS DE PRODUÇÃO DE AMÔNIA
}

Luciane Pimentel Costa Monteiro

\section{Resumo}

O objetivo deste trabalho é apresentar uma ferramenta para a avaliação da eficiência energética em plantas de Amônia através de indicadores chave de desempenho (KPI). O acompanhamento do consumo de insumos na indústria pode levar a reduçóes nas emissóes de gases do efeito estufa (GEE) atrelado a ganhos de eficiência energética nas operaçôes industriais. Ações de monitoramento contínuo focado na gestão por indicadores de desempenho relacionados a dados de emissóes e ao consumo de recursos naturais poderão auxiliar em uma intervenção direta e eficaz e ser um gerador de açóes de melhorias nos processos produtivos e/ou em condutas operacionais. Estas informaçóes quando disponibilizadas para as equipes de operação, em conjunto com açôes de gerenciamento voltadas para a melhoria contínua poderão propiciar ganhos de eficiência energética, redução nas emissóes de gases do efeito estufa e tornar os processos produtivos mais lucrativos.

Palavras-chave: Eficiência Energética. Gases do Efeito Estufa. Indicadores de Desempenho. Processos Industriais.

\begin{abstract}
The purpose of this paper is present a tool for evaluate the energy efficiency using key performance indicators (KPI) to Ammonia plants. Monitoring the consumption of inputs in the industry could generate emissions reductions of greenhouse gases (GHG) linked to energy efficiency gains in industrial operations. Actions focused on continuous monitoring of performance indicators related to emissions data and natural resources consumption allows an effective and direct intervention, and could generate actions in production processes and / or operating practices improvements. Such information when available to operating teams in conjunction with management actions based on continuous improvement could provide energy efficiency gains, reduced emissions of greenhouse gases and make the processes more profitable.
\end{abstract}

Key words: Energy Efficiency. Green House Gases. Key Performance Indicators. Industrial Processes. 


\section{1-INTRODUÇÃO}

Com as crescentes demandas por seus produtos e com as crescentes pressóes para redução de gases de efeitos estufa nota-se uma tendência em investimentos na busca por diminuiçáo dos custos de produção associados a ganhos de produção. Desta forma, avanços no controle dos processos produtivos focado na redução de perdas, monitoramento rígido no consumo de seus recursos e na eficiência energética de seus processos tornam-se atividades essenciais nas rotinas operacionais.

Segundo dados da Society of Petroleum Engineers, a demanda mundial por energia deverá dobrar em 2050. Dados divulgados pela Organização para Cooperação e Desenvolvimento Econômico (OCDE), mostram que as emissóes globais de gases que causam o efeito estufa deveráo aumentar em $50 \%$ até 2050 , principalmente em razão da maior demanda por energia e do crescimento econômico dos grandes países emergentes. De acordo com organização, emissóes de dióxido de carbono $\left(\mathrm{CO}_{2}\right)$, um dos principais gases que provocam o efeito estufa, deverão crescer $70 \%$ até 2050 em razão do aumento no uso de energia. A tabela 1 mostra uma perspectiva de emissão de gás carbônico até 2025 .

A indústria é uma das maiores consumidoras de energia no Brasil e no mundo. O custo da energia pode representar cerca de $10 \%$ dos valores dos custos de produção.

Um insumo bastante comum e muito importante na indústria é o vapor d'água. Utilizado como meio de geração, transporte e utilização de energia. Grande parte da geração de energia elétrica do hemisfério norte utiliza vapor d'água como fluido de trabalho em ciclos termodinâmicos. A geração de vapor é parte importante nas indústrias. Segundo EINSTEN et al (2001). Cerca de $40 \%$ do combustível fóssil queimado na indústria dos EUA é direcionado para a geração de vapor. O vapor gerado, por sua vez, é usado em processos de aquecimento, para concentrar e purificar líquidos, como também pode ser utilizado diretamente como matéria-prima.

Tabela 1 - Emissão de dióxido de carbono por região em milhôes de toneladas métricas de dióxido de

\begin{tabular}{|c|c|c|c|c|c|c|c|c|c|c|c|c|c|c|c|c|c|c|c|c|c|}
\hline Region/Country & 2005 & 2006 & 2007 & 2008 & 2009 & 2010 & 2011 & 2012 & $20203 \mathrm{rb}$ & $201 \mathrm{tan}$ & 02015 & 2016 & 2017 & 2018 & 2019 & 2020 & 2021 & 2022 & 2023 & 2024 & 2025 \\
\hline \multicolumn{22}{|l|}{$\overline{O E C D}$} \\
\hline OECD Americas & 7079 & 7014 & 7123 & 6926 & 6456 & 6693 & 6665 & 6704 & 6748 & 6740 & 6773 & 6814 & 6828 & 6852 & 6880 & 6924 & 6987 & 7022 & 7073 & 7127 & 7169 \\
\hline United States & 5996 & 5918 & 6022 & 5838 & 5426 & 5644 & 5601 & 5622 & 5659 & 5651 & 5680 & 5700 & 5707 & 5724 & 5742 & 5777 & 5825 & 5845 & 5879 & 5914 & 5938 \\
\hline Canada & 620 & 594 & 607 & 595 & 559 & 569 & 570 & 576 & 576 & 571 & 569 & 578 & 578 & 579 & 580 & 582 & 587 & 593 & 598 & 603 & 608 \\
\hline Mexico/Chile & 463 & 502 & 494 & 493 & 471 & 480 & 494 & 506 & 513 & 517 & 524 & 536 & 542 & 549 & 558 & 565 & 575 & 585 & 596 & 610 & 623 \\
\hline OECD Europe & 4400 & 4428 & 4413 & 4345 & 4111 & 4094 & 4097 & 4115 & 4116 & 4118 & 4115 & 4133 & 4135 & 4143 & 4153 & 4147 & 4150 & 4144 & 4150 & 4153 & 4156 \\
\hline OECD Asia & 2172 & 2165 & 2206 & 2201 & 2058 & 2074 & 2112 & 2110 & 2132 & 2145 & 2143 & 2131 & 2134 & 2146 & 2163 & 2181 & 2196 & 2206 & 2213 & 2219 & 2224 \\
\hline Japan & 1241 & 1240 & 1254 & 1215 & 1087 & 1090 & 1114 & 1102 & 1118 & 1128 & 1125 & 1117 & 1117 & 1121 & 1131 & 1142 & 1149 & 1150 & 1146 & 1141 & 1136 \\
\hline South Korea & 494 & 484 & 503 & 522 & 512 & 528 & 539 & 547 & 549 & 550 & 553 & 546 & 547 & 553 & 557 & 562 & 569 & 575 & 582 & 589 & 597 \\
\hline Australia/New & 437 & 440 & 449 & 464 & 459 & 456 & 458 & 461 & 465 & 467 & 466 & 468 & 470 & 472 & 474 & 477 & 479 & 481 & 485 & 488 & 492 \\
\hline Total OECD & 13651 & 13606 & 13742 & 13472 & 12625 & 12861 & 12873 & 12929 & 12996 & 13003 & 13031 & 13079 & 13096 & 13142 & 13196 & 13252 & 13334 & 13373 & 13436 & 13499 & 13549 \\
\hline \multicolumn{22}{|l|}{ Non-OECD } \\
\hline Non-OECD Europe a & 2782 & 2823 & 2790 & 2832 & 2724 & 2759 & 2787 & 2806 & 2802 & 2799 & 2803 & 2776 & 2767 & 2774 & 2772 & 2767 & 2765 & 2763 & 2770 & 2774 & 2782 \\
\hline Russia & 1645 & 1668 & 1618 & 1663 & 1605 & 1632 & 1651 & 1655 & 1650 & 1646 & 1648 & 1623 & 1614 & 1619 & 1614 & 1607 & 1602 & 1597 & 1600 & 1598 & 1603 \\
\hline Other & 1137 & 1155 & 1172 & 1169 & 1119 & 1127 & 1136 & 1151 & 1151 & 1153 & 1154 & 1153 & 1154 & 1155 & 1158 & 1159 & 1163 & 1166 & 1170 & 1176 & 1179 \\
\hline Non-OECD Asia & 8359 & 8835 & 9416 & 10100 & 11154 & 11736 & 11916 & 12185 & 12527 & 12870 & 13238 & 13358 & 13631 & 13913 & 14202 & 14475 & 14817 & 15192 & 15595 & 16034 & 16475 \\
\hline China & 5513 & 5817 & 6257 & 6801 & 7797 & 8262 & 8381 & 8598 & 8853 & 9110 & 9386 & 9382 & 9574 & 9773 & 9961 & 10128 & 10359 & 10617 & 10894 & 11190 & 11492 \\
\hline India & 1182 & 1281 & 1367 & 1462 & 1549 & 1602 & 1633 & 1653 & 1697 & 1756 & 1802 & 1858 & 1902 & 1944 & 1997 & 2056 & 2116 & 2182 & 2250 & 2325 & 2398 \\
\hline Other & 1665 & 1737 & 1793 & 1838 & 1807 & 1872 & 1901 & 1933 & 1977 & 2004 & 2050 & 2117 & 2155 & 2196 & 2244 & 2291 & 2341 & 2394 & 2452 & 2519 & 2585 \\
\hline Middle East & 1400 & 1446 & 1479 & 1581 & 1604 & 1692 & 1743 & 1805 & 1832 & 1861 & 1889 & 1933 & 1944 & 1969 & 1989 & 2019 & 2039 & 2075 & 2111 & 2158 & 2199 \\
\hline Africa & 978 & 984 & 1016 & 1078 & 1062 & 1107 & 1137 & 1165 & 1176 & 1192 & 1209 & 1236 & 1252 & 1270 & 1290 & 1311 & 1333 & 1358 & 1382 & 1409 & 1430 \\
\hline Central a & 1011 & 1064 & 1085 & 1128 & 1111 & 1150 & 1184 & 1223 & 1231 & 1253 & 1287 & 1307 & 1329 & 1352 & 1372 & 1386 & 1394 & 1412 & 1437 & 1466 & 1497 \\
\hline Brazil & 365 & 380 & 397 & 423 & 414 & 440 & 468 & 497 & 505 & 516 & 528 & 531 & 537 & 549 & 563 & 579 & 587 & 599 & 613 & 628 & 644 \\
\hline Other & 646 & 684 & 688 & 705 & 698 & 710 & 716 & 725 & 726 & 736 & 759 & 776 & 792 & 803 & 809 & 807 & 807 & 813 & 824 & 838 & 853 \\
\hline Total Non-OECD & 14530 & 15152 & 15786 & 16718 & 17655 & 18445 & 18766 & 19184 & 19567 & 19974 & 20426 & 20611 & 20922 & 21277 & 21625 & 21958 & 22349 & 22799 & 23294 & 23842 & 24383 \\
\hline Total World & 28181 & 28758 & 29529 & 30190 & 30280 & 31305 & 31640 & 32113 & 32562 & 32977 & 33457 & 33690 & 34018 & 34420 & 34821 & 35210 & 35683 & 36172 & 36730 & 37341 & 37932 \\
\hline
\end{tabular}


Uma análise em sistemas de vapor indica que em uma indústria típica sem uma manutenção preventiva ou preditiva, $28 \%$ dos purgadores de vapor apresentam problemas. Para melhorar o uso do vapor, as indústrias devem empregar um método apropriado para testar os purgadores de vapor para identificar vazamentos, fazer o reparo e quando necessário, fazer a troca dos purgadores que não estejam funcionando corretamente.

A energia elétrica é um insumo essencial para a atividade industrial e a garantia de seu fornecimento, com qualidade, segurança e preços módicos, é fundamental para o desenvolvimento da economia e para o crescimento da produção industrial. O gráfico 1 mostra o consumo de energia elétrica no Brasil e em outros países do mundo.

Gráfico 1 - Tarifa industrial de consumo de energia elétrica - países selecionados $(\mathrm{R} \$$ / MWh)

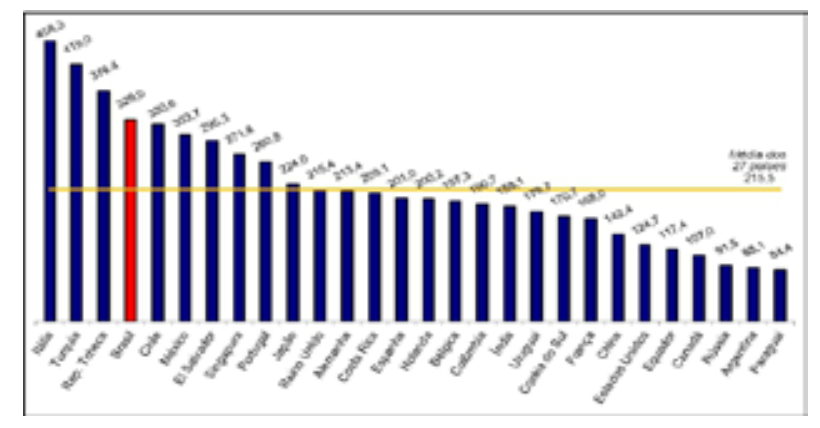

Fonte: Quanto Custa A Energia Elétrica Para A Indústria No Brasil? 2011 - FIRJAN

Nota: Valores convertidos para Real: 1,834 R $\$ /$ US\$ (OCDE, 2011).

Da análise do grafico 1 observar-se que o Brasil possui uma das maiores tarifas de energia elétrica do mundo. Contribui para o alto valor da tarifa os custos com geração, transmissão e distribuição, encargos setoriais, tributos e perdas técnicas.

Uma análise mais detalhada dos processos produtivos podem identificar reduçóes nos custos industriais. Uma estratégia interessante na redução do consumo de insumos concentra-se na eficiência energética, tanto para sistemas novos quanto para os existentes. A eficiência energética pode ser encarada como uma solução interessante gerando retornos atraentes e imediatos, podendo também, proporcionar robustez na sustentabilidade e rentabilidade das operaçốes. Um processo de gestão eficaz começa com uma compreensão e medição do consumo de energia e nas emissóes de GEE e a incorporação desta análise nos processos de tomada das decisóes.

\section{2-USO DE INDICADORES DE EFICIÊNCIA ENERGÉTICA NA INDÚSTRIA}

O consumo de energia nos processos industriais pode ser determinado pelo nível de atividade, estrutura do setor e a eficiência energética. As mudanças no consumo de energia das indústrias não estão exclusivamente relacionadas a eficiência energética nos processos indústriais, mas tambem a fatores políticos, econômicos e ambientais (PHYLIPSEN et al, 1997). Outros fatores devem ser considerados nesta análise como, por exemplo, a capacidade de produção e o tempo de vida da unidade industrial.

A utilização de indicadores voltados para avaliação da eficiência energética de processos na indústria vem crescendo de importância no mundo e no país. Os resultados de uma análise de indicadores de eficiência energética poderão estar ligados a açóes de planejamento estratégico, de gestão e tecnologia ambiental e de conservação de energia. Na prática, cabe destacar que a aplicação da análise destes indicadores e sua relevância em descrever a interelação existente entre eficiência energética e os recursos consumidos associam-se principalmente a fatores econômicos e político-ambientais dentro da indústria.

$\mathrm{O}$ uso de indicadores pode gerar impactos nos processos produtivos. $\mathrm{Na}$ indústria, a análise dos indicadores de eficiência energética pode auxiliar na definiçáo de diretrizes relevantes, tais como:

- direcionar mudanças no consumo energético;

- estabelecer políticas de eficiência energética;

- indicar limitaçóes estruturais que impactam no aumento da eficiência energética;

- substituição de processos tecnológicos;

- alteraçáo no uso e na escolha das matérias prima que são utilizadas nos processos produtivos com o objetivo de reduzir a demanda por energia;

- servir de ferramenta na avaliaçáo de metas para políticas ambientais voltadas para reduçôes de emissôes gasosas. 


\subsection{TIPOS DE INDICADORES DE EFICIÊNCIA ENERGÉTICA}

Os indicadores comumente utilizados para análise de eficiência energética na indústria podem ser subdividos em quatro grupos (GUERRA et al, 2010):

- Termodinâmico;

- Físico-termodinâmico;

- Econômico-termodinâmico;

- Econômico.

Os indicadores que podem ser analisados segundo as leis da termodinâmica estão contemplados no primeiro grupo. Os indicadores físico-termodinâmicos são conhecidos tambem como indicadores específicos. Avaliam o consumo de um determinado insumo relativizado a uma determinada saida (produçáo). $O$ terceiro grupo fornece uma indicação na qual o produto final é mensurado a preços de mercado em relação a unidades termodinâmicas. O quarto grupo de indicadores avalia as modificaçóes causadas pela eficiência energética, em termos monetários, podendo ser considerado para avaliaçáo tanto a energia que entra, quanto a que sai de um determinado processo.

\subsubsection{INDICADORES TERMODINÂMICOS}

A primeira lei da Termodinâmica, também conhecida como princípio de conservação de energia é um princípio geral que não diz respeito ao funcionamento interno do próprio sistema. Sejam quais forem os detalhes do comportamento molecular do sistema, o calor adicionado poderá aumentar a energia interna do sistema, possibilitar que o sistema realize trabalho externo, ou ambos. Para o caso de sistemas isolados, a energia total inicial é igual à energia total do sistema no final do processo, qualquer que seja o caminho seguido pelo sistema para passar do estado inicial ao final. A energia total do sistema é função de estado e náo do caminho seguido pelo mesmo para chegar a esse estado.

Processos termodinâmicos podem ser reversíveis ou irreversíveis. Nos processos reversíveis toda energia convertida de uma forma em outra pode ser aplicada para restaurar o sistema ao estado inicial, sem deixar quaisquer vestígios da ocor- rência do processo. Assim, os processos reversíveis são ideais. Nos processos irreversíveis tal restauração não é possível, porque ocorrem perdas na transformação de uma forma de energia em outra.

$\mathrm{Na}$ realidade, a maioria dos processos industriais tem como desafio superar irreversibilidades. Qualquer transformação energética não deve ser associada a "perda" ou a "gasto" de energia, mas sim a uma degradação energética que impede de realizar, de novo, a mesma transformação, conforme decorre da aplicação da $2^{a}$ Lei da Termodinâmica.

O Teorema de Carnot estabelece um valor de rendimento máximo da conversão de calor em trabalho. É função da temperatura da fonte quente, $\mathrm{Tq}$, e da temperatura de fonte fria, Tf, dado pela seguinte equação:

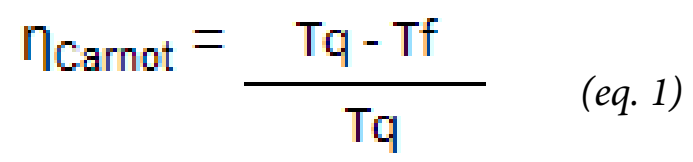

A equação de Carnot estabelece um limite superior de eficiência para todas as máquinas térmicas. Efetivamente, as várias formas de energia não são totalmente convertidas umas nas outras. As formas de energia podem ser convertidas integralmente em calor, mas não se pode converter integralmente calor em outras formas de energia.

A utilização da primeira lei termodinâmica não propicia uma idéia realista de melhorias que podem ser realizadas em um dado sistema para que se obtenha um melhor desempenho. Tal eficiência também náo leva em consideração a qualidade da energia na entrada e na saída do sistema. Não é feita a distinção entre fontes de elevada qualidade energética, que são mais eficientes e produtivas e fontes de baixa qualidade e menos produtivas (ABREU et al, 2010).

A segunda lei da termodinâmica parte do principio que as diferentes formas de energia tem qualidades que lhes são características. Essas formas de energia não podem ser indiferentemente convertidas, umas nas outras e determina a direção que essas transformaçóes podem ocorrer em relação ao Universo. A energia flui sempre de uma maneira que a entropia (grau de randomicidade do sistema) total do sistema aumente para sistemas irreversíveis. Nos processos industriais, de uma forma geral, o efeito da irreversibilidade pode ser verificado uma vez que a conversão de 
energia interna da biosfera (são exemplos recursos fósseis e físseis) passa necessariamente, diante das tecnologias existentes, pelo ciclo térmico irreversível e, portanto, caminha para o aumento da entropia (ABREU et al, 2010).

Neste contexto, esta segunda lei tem como base a definição do limite para os processos. Representando a definição de eficiência termodinâmica e assim, permitindo que se tenha uma idéia das melhorias que podem ser realizadas. Por outro lado sua aplicação é restrita (Patterson, 1996). Correntes defendem o uso de indicadores termodinâmicos, tendo como base de calculo a exergia. A exergia é definida como o máximo trabalho teórico útil obtido quando um sistema é trazido ao equilíbrio termodinâmico com o ambiente por meio de processos nos quais este sistema interage somente com seu ambiente (TOXOPEUS et al, 2006).

$\mathrm{Na}$ engenharia mecânica, uma equação disseminada para cálculo da exergia pode ser representada pela equação 2 :

$$
\left.e x=\left(b-h_{o}\right)-T_{o} *\left(s-s_{o}\right) \quad \text { (eq. } 2\right)
$$

Conforme mostrado na equaçáo acima, exergia $\left(e_{\chi}\right)$ é dependente da entalpia $\left(h\right.$ e $\left.h_{0}\right)$ e entropia $\left(s^{\text {e } ~} s_{0}\right)$ e estas são função da temperatura (T), pressão, estado físico e composição. $\mathrm{O}$ índice subscrito representa as condições de entalpia e entropia nas vizinhanças do sistema.

O conceito de exergia pode ser útil para analisar aspectos relacionados aos ciclos de vida dos produtos uma vez que o conteúdo exergético pode determinar o fluxo de energia perdido.

Partindo-se de um balanço exergético para um sistema hipotético torna-se viável a construção direta de um indicador. A exergia (ex) é a diferença entre o somatório dos fluxos exergéticos que entram no sistema $\left(\sum e x_{e}\right)$ através de fontes de combustível e matérias prima, suas perdas $\left(\sum e_{s}\right)$ e o que é consumido no processo $\left(\sum e x_{c}\right)$.

$$
e x=\sum e x_{e}-\sum e x_{s}-\sum e x_{c} \quad \text { (eq. 3) }
$$

Este indicador não faz distinção entre fontes renováveis e não renováveis. Esta análise pode ser útil para suportar decisóes durante a fase de projeto de equipamentos e processos, do ponto de vista energético. Projetos com minimização da destruição de exergia possuem consumos energéticos menores. Além disso, esta alternativa pro- vavelmente causará o menor impacto ambiental. Porém, segundo Szargut et al (1988) mesmo assim é impossível avaliar exatamente as perdas de exergias atribuídas à diferentes tipos de irreversibilidades, a menos que suposiçôes arbitrárias sejam feitas com a finalidade de separar os fenômenos físicos e químicos.

\subsubsection{INDICADORES FISÍCO- TERMODINÂMICOS}

Esta categoria de indicadores utiliza medidas físicas e termodinâmicas para mensurar o consumo requerido em funçáo do seu uso final. Devido a possibilidade de contabilizar o produto final em quantidades físicas, estes indicadores podem ser comparados e analisados em séries temporais. $\mathrm{O}$ uso de indicadores físico-termodinâmicos para avaliação de desempenhos específicos para o consumo de energia pode ser útil para identificar áreas de baixo desempenho.

A medida da eficiência energética através destes indicadores pode trazer algumas dificuldades em função da sua relação produtiva. A complexidade dos processos produtivos podem ser uma barreira em função da especificação das diferentes entradas e saídas de energia ligadas a diferentes linhas de produção.

$\mathrm{Na}$ indústria, para reduzir falhas na medição entre o consumo de energia e a medida física (produção), este indicador deve ser gerido para medir a eficiência energética global do processo.

\subsubsection{INDICADORES ECONÔMICO- TERMODINÂMICOS}

Estes indicadores relacionam medidas usuais na indústria (medidas termodinâmicas) e a valoração deste insumo e/ou produto final, pois a energia a ser mensurada no sistema pode ser feita em unidades termodinâmicas convencionais e sua saída em valores monetários.

$\mathrm{Na}$ prática, no sentido de se atingir uma economia efetiva de energia na instalação, três fatores adicionais devem ser considerados (LOZANO e VALERO, 1993): (i) nem toda irreversibilidade pode ser evitada; (ii) as reduçóes locais na destruição de exergia não são equivalentes; (iii) as oportunidades de economia só podem ser especificadas através de um estudo mais detalhado dos mecanismos fundamentais da geraçáo de entropia. 
A percepçáo destas fatores levou ao surgimento de metodologias que relacionam a geração de irreversibilidade em um equipamento isolado com o restante dos equipamentos, através da definição do conceito de custo exergético. Concomitantemente, conjugam-se as análises termodinâmica e econômica, relacionando-se o custo monetário e o custo exergético, em um conjunto de metodologias às quais se denomina Termoeconomia (CERQUEIRA, 1999).

A Teoria do Custo Exergético contabiliza as eficiências e perdas exergéticas em cada um dos volumes de controle do sistema (equipamento, conjunto de equipamentos, ou junçóes e bifurcaçóes), tendo como resultado o custo exergético de produção de cada um dos fluxos (portadores de energia). Outro aspecto deste método é que a medida do custo de um fluxo do sistema está representada pela exergia contida nele. Em uma análise do custo exergético, um custo é associado com cada fluxo de exergia.

Considerando os fluxos de matéria entrando e saindo $\left(\mathrm{c}_{\mathrm{e}}, \mathrm{c}_{\mathrm{s}}\right)$ com taxas associadas de transferência de exergia $\left(B s\right.$ e $\left.B_{e}\right)$, potência $(W)$, taxa de transferência de exergia associada com a transferência de calor $\left({ }^{c} Q\right)$, um componente que recebe uma transferência de calor e gera potência, como também as expressóes de taxa de custo, tem-se:

$$
\begin{aligned}
& {\left[\sum\left(c_{s} B s\right)_{k}\right]_{s}+c_{w, k} W={ }^{c} Q, k^{B} Q, k} \\
& {\left[\sum\left(c_{e} B_{e}\right)_{k}\right]_{e}+Z_{k}}
\end{aligned}
$$

As taxas de exergia $\left(B s\right.$ e $B_{e}$ e $B Q$ ) saindo e entrando no k-ésimo componente, bem como a potência $(W)$, são calculadas em uma análise exergética. O termo $Z_{k}$ é obtido, primeiramente, calculando o investimento de capital associado com o k-ésimo componente e, então, computando os valores particionados destes custos por unidade de tempo de operação do sistema.

\subsubsection{INDICADORES ECONÔMICOS}

Esses indicadores têm como característica principal a mensuração da energia de entrada e saída em valor monetário.

Por ser uma categoria de indicadores puramente econômicos leva-se ao questionamento de ser ou não um indicador de eficiência energética. Por exemplo, o indicador econômico para uma indústria ou setor é determinado pelos preços dos produtos finais multiplicado pela quantidade total dos mesmos. Isso torna os valores finais encontrados através destes indicadores econômicos / energéticos vagos, se utilizados sozinhos sem outra análise complementar, porque os preços podem variar e a qualidade do produto também, não refletindo assim, a eficiência energética.

Segundo estudo realizado por World Energy Council (2004), para definir e caracterizar a eficiência energética pode-se utilizar macroindicadores que reportam a economia como um todo (macroeconomia) ou os principais setores (industrial, agrícola, etc.) ou somente os principais usos finais.

Existem também os microindicadores que podem ser definidos como microeconômico. Estes englobam, nessa área de eficiência energética, os seguintes itens:

- Comportamento do consumidor em relaçáo ao preço da energia e a utilização de aparelhos mais eficientes.

- Determinaçáo dos custos marginais da energia, dos de capacidade e dos de expansão para uma estrutura desagregada (custo incremental unitário).

- As implicaçóes das variáveis do modelo de equilíbrio geral, que determinam os preços sombras, para o consumidor final. Como: preços eficientes, preços sociais e outras.

- Curvas de oferta e demanda para a energia.

- Previsão de demanda de energia.

Os indicadores microeconômicos podem também ser utilizados como ferramentas para a prática de engenharia econômica, medindo-se o custo efetivo de investimentos de eficiência energética, como: o retorno do investimento simples, o custo de energia economizada (CEE), a taxa interna de retorno (TIR) e o custo do ciclo de vida (CCV) ou o custo de vida anual (CCVA). Assim, esta metodologia poderá auxiliar no processo decisório da tecnologia a ser empregada e o melhor investimento a ser feito.

\section{3-OBJETIVO}

Este trabalho tem por objetivo apresentar um estudo da eficiência energética em plantas de produção de Amônia utilizando como ferramenta indicadores de desempenho físico-termodinâmicos. 


\section{4-METODOLOGIA}

O cálculo da eficiência energética líquida considerou para o cálculo os termos referentes a produção anual de Amônia e a energia utilizada. Todas as alimentaçóes e os combustíveis consumidos para uma planta de produção de Amônia foram considerados neste estudo.

Para a contribuição das parcelas de energia no cálculo do indicador foram considerados as parcelas referentes a energia para a produção de Amônia, a energia utilizada para partida da planta, energia consumida durante paradas não programadas, reduçóes de catalisador, dentre outras.

Neste trabalho, a avaliação da eficiência energética em plantas de produção de Amônia considerou o desempenho anual em detrimento a eficiência dos projetos.

Para viabilizar a análise entre as diferentes plantas foi necessário elaborar uma base comparativa. Esta normalização foi realizada em função das diferentes configuraçóes das plantas analisadas. Abaixo são apresentadas tais consideraçóes:

- Eletricidade importada convertida em calor equivalente com $40 \%$ da eficiência de tomando como base o poder calorífico inferior do combustível;

- Importação e exportação de vapor corresponde a $90 \%$ da eficiência de conversão sendo considerado como referência vapor saturado a $15^{\circ} \mathrm{C}$;

- A base considerada para produção de Amônia é $100 \%$ líquida na condição de pressão atmosférica $\left(-32^{\mathrm{O}} \mathrm{C}\right)$;

- A energia para produzir e bombear água de resfriamento foi considerada na parcela de cálculo referente ao uso de energia;

- A parcela de energia para produzir e bombear água de alimentação para as caldeiras foi considerada no cálculo referente ao uso de energia;

Não foram realizados ajustes em função da diferentes tecnologias, clima, condiçôes de catalisador ou problemas operacionais.

\section{5-RESULTADOS E DISCUSSÓES}

Para a análise da eficiência energética foram consideradas 50 plantas de Amônia e suas produçóes individuais anuais. $\mathrm{O}$ indicador de eficiencia energética foi calculado conforme a equação a seguir:

\section{EFICIÊNCIA ENERGÉTICA:}

\section{$\left(\mathrm{GJ} / \mathrm{t} \mathrm{NH}_{3}\right)=\underline{\mathrm{MP}}+\mathrm{C}+\mathrm{OUTROS}$ $\mathrm{PROD} \mathrm{NH}_{3}$}

Onde,

MP - é a conversão de matéria prima consumida em energia equivalente considerando o poder calorífico inferior.

C - é a conversão de combustível utilizado no processo em energia equivalente considerando o poder calorífico inferior.

OUTROS - são outras energias consideradas no processo tais como eletricidade e vapor importados, crédito por exportação de energia (por exemplo, vapor), geração e bombeamento de água para alimentação das caldeiras e água de resfriamento.

PROD DE $\mathrm{NH}_{3}$ - é a produção de Amônia expressa em toneladas.

A parcela a produção de Amônia considerou a produção diária máxima em detrimento da capacidade de produçáo de projeto da planta. As plantas foram separadas em 3 categorias. Das 48 plantas avaliadas, 12 foram classificadas como pequenas com produçáo inferior a 1000 t/dia. 17 plantas foram consideradas como intermediárias apresentando produçáo entre 1000 t/dia e 1500 t/ dia. E 19 plantas com produção superior a 1500 t/dia foram consideradas como grande. As capacidades de produçáo anuais das plantas de Amônia estão apresentadas no gráfico 3. A variação de produção ficou entre 91000 t/ano e 749800 t/ano.

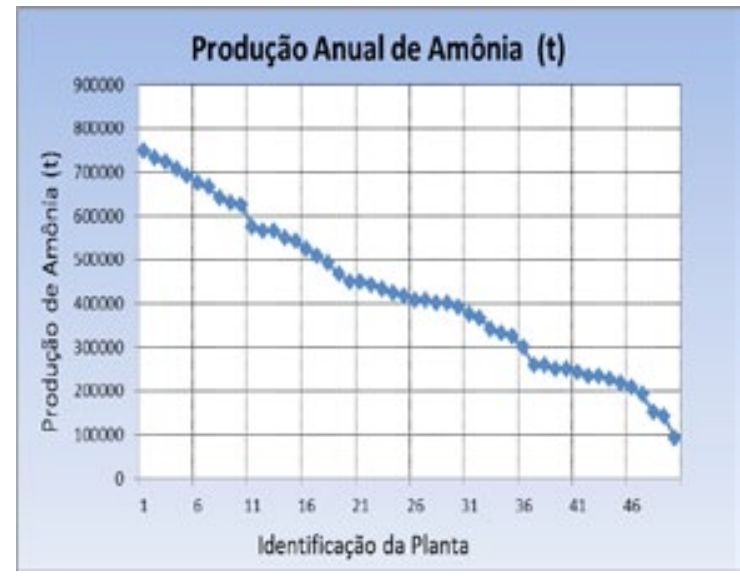

GRAFICO 3: Produção Anual de Amônia (toneladas)

Os valores encontrados na avaliaçáo do indicador de eficiência energética ficaram entre 23,8 
$\mathrm{GJ} / \mathrm{t} \mathrm{NH}_{3}$ e $51,9 \mathrm{GJ} / \mathrm{t} \mathrm{NH}_{3}$. Das 50 plantas analisadas, sendo 2 delas utilizam hidrogênio puro ou gás rico em hidrogênio como matéria prima. Estas plantas normalmente apresentam índices de eficiência energética maiores se comparado com as outras plantas. Já as 48 plantas convencionais de Amônia utilizam matérias primas diversas como gás natural e óleo pesado oriundo do fracionamento de petróleo.

A seguir, o gráfico 4 mostra o indicador de eficiência enegética para cada planta de Amônia.

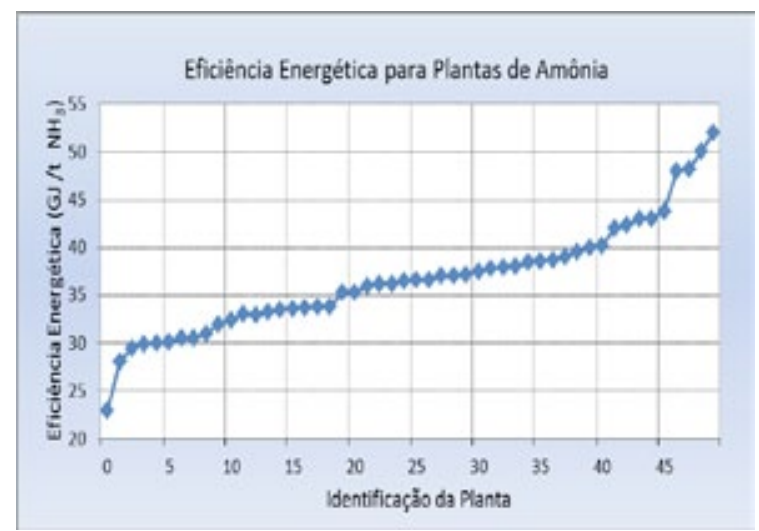

GRAFICO 4: Eficiência Energética (GJ / t NH3) para Plantas de Amônia

A relação entre capacidade e eficiência energética para as 48 plantas de Amônia convencionais é mostrada no gráfico 5 .

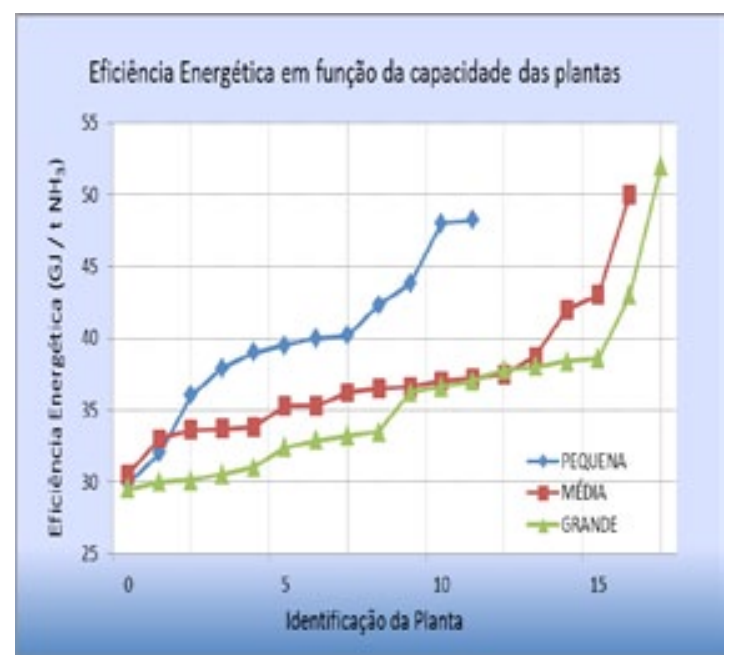

GRAFICO 5: Eficiência Energética (GJ / t NH3) em função da capacidade de Plantas de Amônia

Da análise do gráfico 5 verifica-se que existe uma relação entre a capacidade e a eficiência energética da planta. De uma forma geral, plantas com maior capacidade apresentam maior eficiência energética e plantas de menor capacidade são menos eficientes. No entanto, as melhores plantas em cada grupo apresentam índices de eficiência energética que variam entre 29,5 GJ/t $\mathrm{NH}_{3}$ e $30,6 \mathrm{GJ} / \mathrm{t} \mathrm{NH}_{3}$ indicando que plantas com capacidade inferior a $1.000 \mathrm{t} / \mathrm{dia}$ podem ser eficientes.

O grafico 6 apresenta o cálculo do indicador de eficiência energética em função da idade de cada planta. A idade de cada planta varia entre 1,5 e 39 anos. As plantas foram divididas em três categorias. As classificadas como novas possuem idade inferior a 14 anos. As chamdas médias possuem idade entre 18 e 29 anos e as antigas acima de 30 anos.

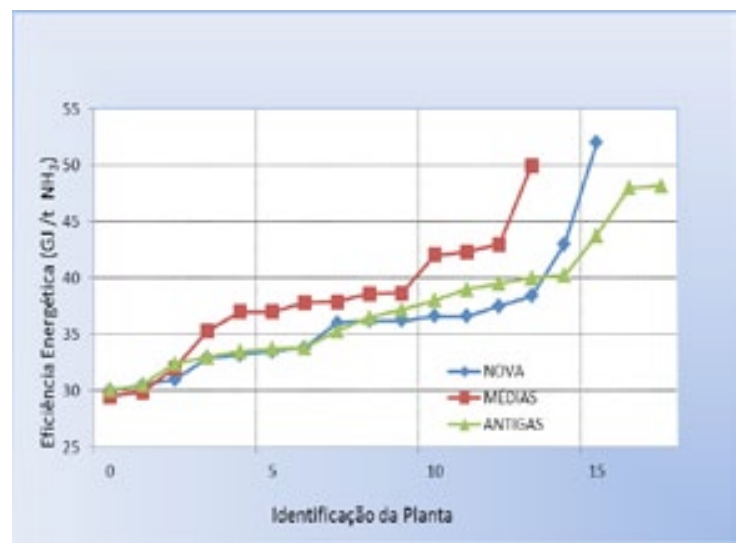

GRAFICO 6: Eficiência Energética em função da idade das Plantas

Das 48 plantas de amônia convencionais analisadas, as plantas classificadas como novas apresentaram melhor média para $\mathrm{o}$ indicador de eficiência energética líquida $36,0 \mathrm{GJ} / \mathrm{t} \mathrm{NH}_{3}$ para 16 plantas analisadas neste grupo. As plantas classificadas com tempo de operação intermediário (14 plantas) apresentaram índice médio de 37,7 $\mathrm{GJ} / \mathrm{t} \mathrm{NH}_{3}$. E as plantas com maior tempo de operaçáo apresentaram um resultado médio de 37,4 $\mathrm{GJ} / \mathrm{t} \mathrm{NH}_{3}$.

As melhores plantas de cada grupo apresentam índices de eficiência energética em cerca de $30 \mathrm{GJ} / \mathrm{t} \mathrm{NH}_{3}$. Esta observação indica que plantas com maior tempo de operação, através de modificações e melhorias nos processos podem operar com bons índices de eficiência energética.

\section{6-CONCLUSÓES}

Neste trabalho foi apresentada uma avaliação da eficiência energética para plantas de Amônia através do uso de indicadores. Dados de 50 plantas de Amônia foram considerados neste estudo. Este 
indicador tomou como base a produçáo anual de Amônia e a medida da energia consumida considerando quantidades de energia equivalente no consumo de matérias primas, combustíveis e em outras formas presentes no processo (consumo de energia equivalente para a geração e distribuição de água de resfriamento, importação ou exportaçáo de vapor, dentre outros). Foi criada uma base comparativa em função das diferentes configuraçóes das plantas analisadas. Outros índices comparativos foram levantados tomando-se como base a eficiência energética. Foram apresentados índices de eficiência energética em função do tempo de operação das plantas assim como a avaliação de eficiência energética em função da produção anual. Constatou-se que há uma relação direta entre capacidade de produção e eficiência energética. Outra constatação apresentada neste foi que plantas com longo tempo de operação apresentaram índices de eficiência energética comparados a plantas mais novas indicando melhoria em seus processos (equipamentos) e em suas rotinas de operação. Do resultado da análise por indicadores pode-se obter uma ferramenta útil na avaliação da melhoria continua dos processos do ponto de vista da eficiência energética.

\section{7-REFERÊNCIAS}

ABREU, Y. V.; OLIVEIRA, M. A. G.; GUERRA, S. M. G.,(2010); Energia Sociedade E Meio Ambiente. EUMED.NET, UNIVERSIDADE DE MALAGA .

CERQUEIRA,A.G.(1999)Metodologias de Análise Termoeconômica de Sistemas; Tese de doutorado, Faculdade de Engenharia Mecânica, UNICAMP.

ENISTEIN, D. ,(2001); WORRELL, E. ; KHURSHCH, M.; Steam systems in industry: Energy use and energy efficiency improvement potentials; Lawrence Berkeley National Laboratory

ENERGY EFFICIENCY: a worldwide review indicators, Policies evaluation (2004) Relatório emitido pelo World Energy Council em colaboração com ADEME.
INDUSTRIAL ENERGY, INDUSTRIAL EFFICIENCY: Indicators for a European cross-country comparison of energy efficiency in the manufacturing industry(1997). Energy Policy, vol 25

LOZANO, M.A., VALERO A.(1993); Theory of Exergetic Cost: Energy, Vol.18

NANOTECH DO BRASIL. Eficiência Energética - Energia Útil - MME. Disponível em: http:// www.nanotechdobrasil.com.br/eficiencia-energetica-energia-util-mme/. Acesso em 13 de junho de 2012.

PHYLIPSEN, G.J.M.; BLOK, K.; WORRELL, E.(1997) - International comparisons of energy efficiency- Methodologies for the manufacturing industry .

SCIUBBA, E.; WALL, G. - A brief commented history of exergy from the beginnings to 2004.,(2007) International Journal of Thermodynamics, Vol. 10.

SZARGUT J., MORRIS R.D., STEWARD F.R. (1988)- Exergy analysis of thermal, chemical, and metallurgical processes.Springer-Verlag

TOXOPEUS, M. E., LUTTERS, E., HOUTEN, F.(2006) - Environmental Indicators \& Engineering: an Alternative for Weighting Factors, 13th International Conference on Life Cycle Engineering, Vol. 75.

UCHOA, T. B, BENEDUZZI, A. H., MASHIBA, M. H. da Silva et al.(2006). Análise termodinâmica e termoeconômica de uma usina sucroalcooleira que produz excedente de bagaço para comercializaçáo. Encontro De Energia No Meio Rural, 6, Campinas.Disponível: http://www.proceedings.scielo.br/scielo.php?script $=$ sci $\operatorname{arttext\& ~}$ pid=MSC0000000022006000100014\&lng=en \&nrm=abn . Acesso em 15 de junho de 2012. 